\title{
Incidentally detected congenital left atrial appendage aneurysm
}

\author{
Senthil Kumar Aiyappan · Upasana Ranga • Saveetha Veeraiyan
}

Received: 11 September 2013 / Accepted: 19 October 2013 / Published online: 16 August 2014

(C) Indian Association of Cardiovascular-Thoracic Surgeons 2014

\begin{abstract}
A 22-year-old male patient was referred to us for cardiac computed tomography (CT) angiography since chest radiograph showed prominent left cardiac border. Patient was asymptomatic and chest radiograph was done as a routine health checkup. Laboratory findings were within the normal range. Electrocardiograph (ECG) showed normal sinus rhythm.
\end{abstract}

Cardiac CT angiography revealed a $9 \times 8 \times 6 \mathrm{~cm}$ sized left atrial appendage aneurysm communicating with left atrium (Figs. 1a and 2). There was associated partial thrombus within the aneurysm (Fig. 1b). Echocardiography showed left atrial aneurysm with partial thrombus and normal cardiac valves. Due to the potential risk of embolism, the patient was referred for surgical resection of the aneurysm.

S. K. Aiyappan $(\varangle) \cdot U$. Ranga $\cdot S$. Veeraiyan

Department of Radiodiagnosis and Imaging, Saveetha Medical College and Hospital, Thandalam, Kancheepuram,

Tamilnadu 602105, India

e-mail: senthilkumarpgi@yahoo.co.in

\section{U. Ranga}

e-mail: upasranga@yahoo.co.in

S. Veeraiyan

e-mail: saveetha75@gmail.com

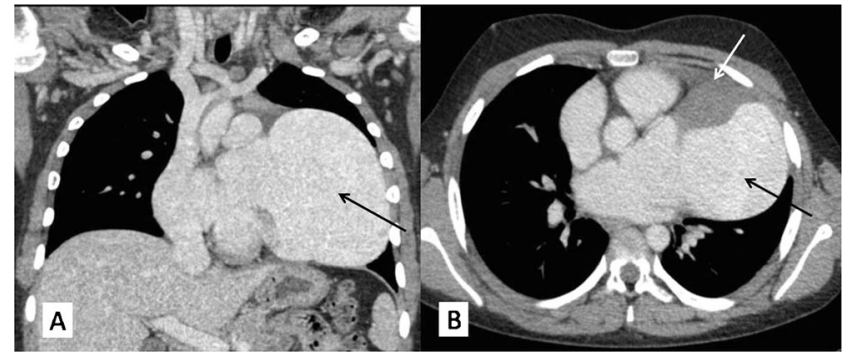

Fig. 1 a Coronal multiplanar reformatted and $\mathbf{b}$ axial cardiac CT angiography images showing the presence of left atrial appendage aneurysm (black arrows) communicating with left atrium. Hypodense filling defect noted within the aneurysm suggestive of partial thrombus (white arrow)

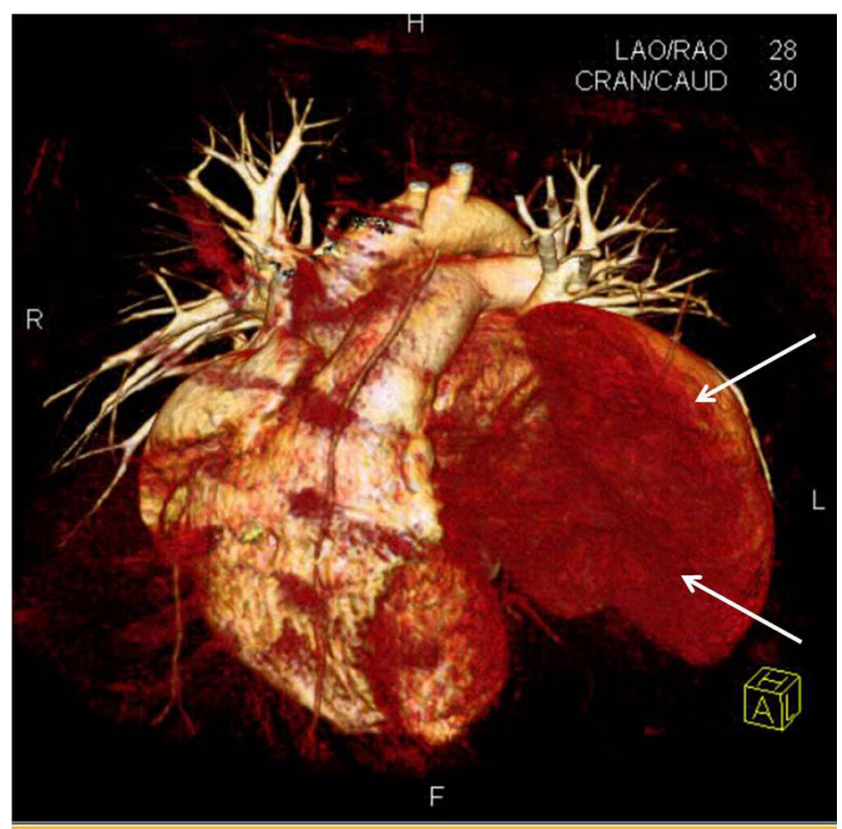

Fig. 2 Coronal volume rendered cardiac CT angiography image showing the presence of large left atrial appendage aneurysm (white arrows) 